\title{
EFFECTS OF FLOWERS ON PARASITOID LONGEVITY AND FECUNDITY
}

\author{
S.D. WRATTEN ${ }^{1}$, B.I. LAVANDERO ${ }^{1}$, J. TYLIANAKIS ${ }^{1}$, D. \\ VATTALA $^{1}$, T. ÇILGI ${ }^{2}$ and R. SEDCOLE ${ }^{3}$ \\ ${ }^{1}$ National Centre for Advanced Bio-Protection Technologies, PO Box 84, \\ Lincoln University, Canterbury, New Zealand \\ ${ }^{2}$ School of Biological Sciences, University, Southampton, S02 1PF, U.K. \\ ${ }^{3}$ Applied Computing, Mathematics and Statistics Group, PO Box 84, Lincoln \\ University, Canterbury, New Zealand \\ Corresponding author: wrattens@lincoln.ac.nz
}

\begin{abstract}
Conservation biological control (CBC) enhances biological control efficacy by providing pollen, nectar, shelter and/or alternative prey to biological control agents. It is a fast-growing sub-discipline of biological control, with notable recent successes. In contrast, classical biological control, in spite of its long history, has not risen above a $10 \%$ success rate since 1880 and can have much-publicised negative consequences. This paper presents recent data on $\mathrm{CBC}$ research in brassicas in New Zealand and discusses how understanding and effectiveness can be improved. The provision of floral nectar to parasitoids such as Diadegma can enhance longevity from two days in the presence of water only to 30 days, and can lead to higher fecundity. The paper outlines key research questions for the future.
\end{abstract}

Keywords: conservation biological control, brassicas, grassland.

\section{INTRODUCTION}

'What good are all those species that man cannot eat or sell?' E.P. Odum

Ecosystem services (ES) (Farber et al. 2002) incorporate the production of primary goods such as food, fibre and bio-energy, and the regulatory effects that ecosystems have on biogeochemical (e.g. clean air and water and healthy soil) and pest/disease cycles. Also included in ES are the human subjective cultural services of landscape aesthetics (current and historical) and diversity. Biological control is a key ecosystem service and has been an important approach for managing insect pest populations for more than 100 years (Hawkins et al. 1999). However, the rate of success (measured in terms of 'some effect' of new natural enemies) in "classical" biological control from 1880 to the present has been only around $10 \%$, with no significant improvement in success rate over that period (Gurr et al. 2000a, 2000b). There are many factors that can explain this low success rate, one of which could be the lack of ecological knowledge of the requirements of the agents involved.

Recently, an increased effort has been made to study the ecology of naturally occurring and introduced enemies of pests, in order to preserve or enhance the enemies' efficiency (Ehler 1998; Gurr \& Wratten 2000; Landis et al. 2000). Conservation biological control involves environmental manipulation to enhance the fecundity and longevity of natural enemies, modify their behaviour and provide shelter from adverse environmental conditions. Food webs are 'engineered' via the provision of 'resource subsidies' to increase the effect of natural enemies on pest populations, potentially mitigating harmful conditions (such as pesticides) or enhancing favourable influences on the natural enemies' fitness and efficacy. CBC effectively exploits the 'life-history omnivory' of natural enemies (Waage 1990) by understanding the different feeding requirements of adult and 
larval predators and parasitoids. This enhancement can be achieved by providing the "right" diversity of alternative food sources, shelter and microclimate and alternative prey or hosts (White et al. 1995; Hickman \& Wratten 1996; Landis et al. 2000). Providing the 'right' diversity includes the provision of pollen and nectar resources that benefit the natural enemies but not the pest (Speight 1983; Baggen \& Gurr 1998). Shelter is also very important, so that natural enemies can persist from year to year in perennial and annual crops. Among the successful attempts to provide shelter for natural enemies is the use of 'beetle banks' that consist of perennial grasses sown on a raised earth bank (Thomas et al. 1992; Landis et al. 2000).

\section{Habitat manipulation}

Habitat manipulation produces effects that are consistent with the 'resource concentration' hypothesis (Root 1973). These effects are termed 'bottom-up', as herbivore populations are determined by a lower trophic level, through mechanisms such as interference with host-plant finding of herbivores. The idea of diluting the crop resource, reducing the contrast between a concentrated crop and the soil, interrupts the visual and chemical stimuli to the pest, resulting in a reduction in damage to the crop (Andow 1991; Gurr et al. 2000a). There are many studies that suggest that these mechanisms are important (Andow 1991), but this approach needs to be distinguished from conservation biological control, which generates 'top-down' effects, referred also as the 'enemies hypothesis' (Root 1973). These specifically involve maximisation of the impact of natural enemies by providing key ecological resources and by minimising pesticide-induced mortality (Gurr et al. 2000a; Landis et al. 2000).

\section{A REVIEW OF CONSERVATION BIOCONTROL PRACTICES \\ The role of non-host resources for parasitoids}

The survival and activity of parasitoids is influenced by the availability and quality of water and food (pollen and nectar), habitat requirements and intra- and inter-specific competition (Altieri et al. 1993). Information on the range of foods that adult parasitoids exploit is limited to a small number of species, despite the importance of adult nutrition in the ecology of these organisms (Jervis \& Kidd 1999).

There is empirical support that consumption of non-host foods leads to increases in the rates of parasitism and to decreases in host densities. Several studies in the laboratory and in the field have demonstrated higher rates of parasitism when non-host resources are available compared with when they are less available or absent (see Jervis \& Kidd 1999; Landis et al. 2000). However, it has been much more difficult to prove in all cases that the higher parasitism levels lead to improved host population suppression (Jervis \& Kidd 1999).

As sugar sources can be highly variable in quantity, space and time, the chances of finding an amount of sugar sufficient to increase longevity (Jervis \& Kidd 1999) from a single feeding event can be critical for the forager's fitness. Siekmann et al. (2001) measured longevity of the parasitoid Cotesia rubecula (Marshall) when fed with different sugar concentrations and at different times, and found that the risk of starving to death in sugar-fed wasps was reduced by $0-73 \%$ in comparison with unfed wasps. Longevity was significantly increased by sugar concentration and by feeding later in life, suggesting that in the field, adult $C$. rubecula has to locate food at least once per day to avoid starvation. This provides evidence for the importance of non-host resources to the parasitoids.

Nectar is an important food source for adult Hymenoptera (Kevan \& Baker 1984), so the final decision in selecting plant species for the enhancement of biocontrol will have to consider flower, pest and parasitoid phenology and nectar quality and availability (Colley \& Luna 2000). A better knowledge of which part of the flower is used by the parasitoids will help the selection of the "right" flowering plants for parasitoid population enhancement and improved efficacy. Using the anthrone test it is possible to determine whether parasitoids are using nectar. If pollen is the preferred food source, dissections of the abdomen followed by saffranin staining (see Wratten et al. 2003) can facilitate the identification of the ingested pollen grains. 
Although CBC is a rapidly-expanding component of the science of biological control, and has had some notable successes (e.g. 'beetle banks'; Thomas et al. 1992), some key questions remain. For example, while the fitness of parasitoids and predators can be dramatically improved via the provision of pollen or nectar (Hickman \& Wratten 1996; Berndt et al. 2003), the question of the arrangement of these 'resource subsidies' in the landscape remains largely unanswered. This landscape-design element depends heavily on the dispersal ability of natural enemies after they have received the resource subsidy. Sophisticated marking methods are required to assess this. Some of these methods involve the laborious marking of individual insects, while others involve the insect marking itself, and this can lead to hundreds of individuals being marked per hour, independent of the researcher (Wratten et al. 2003). A timely review of these methods will appear in a special issue of the International Journal of Pest Management (Lavandero et al. in press).

As discussed above, there is good recent evidence for substantial improvement of parasitoid fitness following the provision of floral nectar and some recent examples of this are given below. However, the criteria for the selection of the flower species to be used are complex and range from ecological to agronomic considerations. A preliminary outline of these criteria was given in Gurr et al. (2000).

\section{Characteristics of the parasitoid/predator in relation to floral use}

Mouthpart morphology and body size. The parasitoid needs to be able to access the floral nectaries. Flowers with shallow corollae are often selected by researchers for this reason but detailed work is rarely carried out. Plants which have been used successfully in CBC, such as Phacelia tanacetifolia Benth.: Hydrophyllaceae, have provided pollen for predators (Hickman \& Wratten 1996; Wratten et al. 2003) but sometimes have deep corolla tubes. It is assumed that some parasitoids cannot access these nectaries but this has rarely been investigated.

Aggregative numerical responses (sensu Solomon 1969). The extent to which natural enemies are attracted to particular flowers and the stimuli involved are often underresearched, with flower species choice often being based on agronomic criteria.

Dispersal rate of the natural enemy. A basic tenet of $\mathrm{CBC}$ is that, following the acquisition of resource subsidies, natural enemies will disperse into the adjacent cropping system. The distance over which this dispersal takes place will determine the spatial arrangement and overall quantity of resource subsidies needed (Lavandero et al. in press). Plant characteristics and agronomy

Annual/perennial. Depending on the cropping system, one or both of these plant types may be appropriate. Perennial plants may spread beyond their initial location, may interfere with farm machinery or may harbour invasive weeds. However, their use removes the need for re-drilling every season. Annual plants often have the opposite characteristics.

Weed potential. Annual plants such as buckwheat (Fagopyrum esculentum Moench.) germinate and grow quickly but are killed by frost in most climates, so are less likely to become persistent weeds. In contrast, $P$. tanacetifolia (see above) produces seeds readily and can survive frosts. Its seeds can remain in the seed bank for many years and can contaminate annual and perennial crops.

Floral architecture. As discussed above, corolla structure may suit some parasitoids but exclude others. Laboratory experiments are often the first step in screening plants for this characteristic.

Pollen/nectar quality, quantity and nectar flow. This is rarely investigated in CBC research but should be part of initial laboratory screening in relation to parasitoids or predators. In most published examples of CBC, it is not known how nectar flow rate varies over 24 hours and whether nectar is, in fact, actually available to natural enemies for most of the diurnal period. A recent study (J. Lee \& G. Heimpel, pers. comm.) demonstrated that the nectar availability of buckwheat was high during the morning and decreased later, suggesting that nectar availability was limited by its removal by insects. Does the plant harbour the target pest or other pests?

If the added flowering species is closely related to the studied crop, and/or if the pest 
is polyphagous, the plant providing the 'resource subsidy' may also be a resource for the pest (Baggen \& Gurr 1998).

\section{A hierarchy of 'measures of success'}

Using floral resource subsidies as the example, a logical hierarchy for measuring the success of $\mathrm{CBC}$ would be to answer the following questions:

- Does the adult parasitoid/agent use floral resources?

- Does it use pollen and/or nectar?

- How compatible is the agent with the use of some pesticides, including the way its dose-response curve can be exploited in reduced-rate pesticide use. The latter was demonstrated for a range of insect predators by Poehling (1989).

- Is the fitness of individual agents improved? If so, are there improvements in longevity, fecundity, sex ratio (next generation), searching efficacy, digestion rates, etc.?

- Does the improved fitness apply to males and females?

- Are pest populations reduced as a result of CBC?

- Are pest populations reduced to below the economic threshold?

- Does CBC improve farmers' profits?

\section{CURRENT CBC WORK FROM NEW ZEALAND}

\section{Objectives}

The effect of different food sources on the longevity and fecundity of Diadegma semiclausum (Helen), a parasitoid of the diamondback moth (Plutella xylostella (L.)), and Microtonus hyperodae Loan, a parasitoid of Argentine stem weevil (Listronotus bonariensis (Kuschel)), was determined.

\section{Materials and methods}

No-choice experiments were conducted in the laboratory on D. semiclausum and $M$. hyperodae at $20^{\circ} \mathrm{C}$ (with a $4^{\circ} \mathrm{C}$ range) at $16: 8 \mathrm{~h}$ light:dark photoperiod. The flowers and the insects were enclosed in a cylindrical cage $(20 \mathrm{~cm}$ high and $9 \mathrm{~cm}$ in diameter). Cages consisted of an acetate sheet with fine mesh on the top and foam on the bottom. A $4 \mathrm{~cm}$ slit in the foam from the edge to the centre, was cut to allow the insertion of the flower shoots (see below). A $2 \mathrm{~cm}$ hole was made on the side of the cage to allow the introduction of insects and was normally plugged with cotton wool. Treatments consisted of buckwheat (Fagopyrum esculentum Moench cv. Katowase), diluted honey (10\% v/v) and water. In the case of $M$. hyperodae the honey treatment was diluted honey $(50 \% \mathrm{v} / \mathrm{v})$. For the honey and water treatments, $50 \mathrm{ml}$ vials with a cotton wick were placed inside the cages. Vials and flower shoots were changed every three days. One male (except for $M$. hyperodae) and one female parasitoid per treatment (18 pairs total) were checked daily to assess longevity. A total of 45 females was dissected 6, 12, 24, 48 and 72 hours after emergence to ascertain potential fecundity in D. semiclausum.

Mean longevities and associated standard errors were calculated from the analysis of survival time (GenStat procedure RSURVIVAL). For potential fecundity, the data for egg number were analysed using the generalized linear model routine in GenStat (GenStat Release 6.1, 2002, Lawes Agricultural Trust, Rothamsted Experimental Station). The routine was used to determine the significances of main effects and interactions, and to estimate mean counts and approximate standard errors for the figures.

\section{Results and discussion}

The mean longevity for $D$. semiclausum feeding on buckwheat (Fagopyrum esculentum Moench cv. Katowase) flowers was 15/14.2 (male/female) times greater (30.3/25.6 days) than the mean longevity with only water (2.0/1.8 days (male/female)) (Fig. 1). There was a highly significant effect of the feeding treatment (deviance $=51.23, \mathrm{df}=8, \mathrm{P}<0.001$ ), but no significant effect of sex (deviance $=0.68, \mathrm{df}=1, \mathrm{P}=0.4$ ), nor for the interaction (deviance $=0.99, \mathrm{df}=8, \mathrm{P}=0.99$ ). Within the treatments, there was a highly significant difference in mean longevity between water and honey ( $\mathrm{t}=3.87, \mathrm{P}<0.001$ approximately), and between water and buckwheat ( $\mathrm{t}=4.71, \mathrm{P}<0.001$ approximately), but no significant difference between buckwheat and honey (Fig. 1). The fecundity data show that buckwheat could be a potential plant for enhancing fecundity of the parasitoids (Fig. 2). 
There were highly significant effects of treatment (deviance $=349.9, \mathrm{df}=4, \mathrm{P}<0.001$ ), hours after emergence (deviance $=43.7, \mathrm{df}=2, \mathrm{P}<0.001$ ) and the interaction (deviance $=38.7, \mathrm{df}=8, \mathrm{P}<0.001$ ). These data also suggest that $D$. semiclausum is a synovogenic species, so provision of floral resources, for egg maturation and subsequent potential higher parasitism rates, is very important.

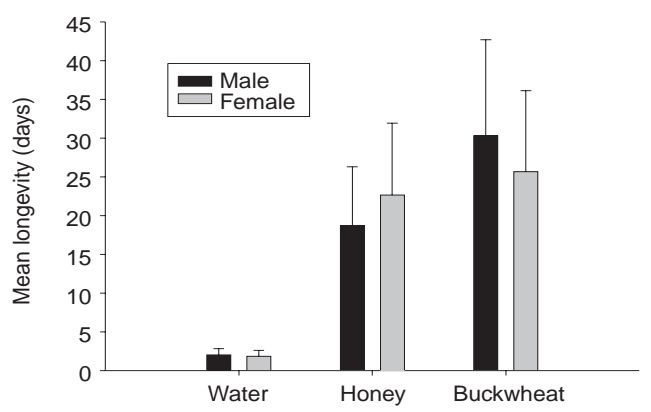

FIGURE 1: Mean longevity of adults of male and female Diadegma semiclausum with different food resources. Error bars shown are \pm one SE.

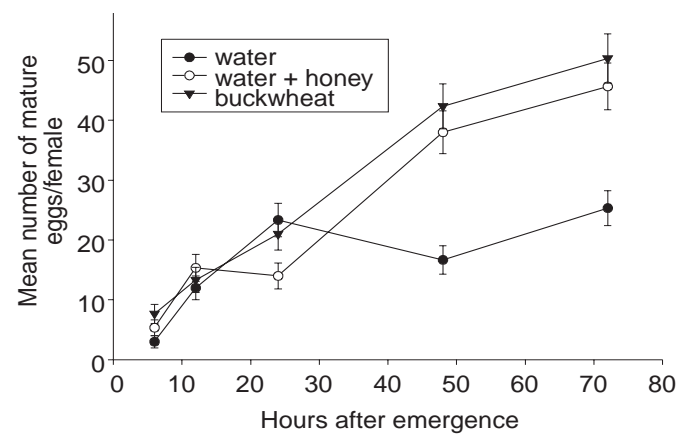

FIGURE 2: Mean number of eggs at different times after emergence of females of Diadegma semiclausum with different food sources. Error bars shown are \pm one SE.

Flowers increased longevity in $M$. hyperodae. Mean longevity was 6 days with only water, 9 days with the brassica Choi Sum and with 50\% honey, and 12 days when given access to buckwheat flowers. This suggests that buckwheat doubled the longevity of $M$. hyperodae compared with water and work is continuing. Previous results showed that under laboratory conditions, the longevity of $M$. hyperodae increased significantly $(\mathrm{P}<0.05)$ from 4 to 17 days by provision of liquid food (Hodgson \& Potter 1993).

The preliminary results presented here are examples of the type of effects that floral resources can have on parasitoids in the laboratory. Work in progress is investigating many of the aspects outlined in the 'measures of success' hierarchy given above. Progress to date is reviewed in Wratten et al. 2000. 


\section{REFERENCES}

Altieri, M.A.; Cure, J.R.; Garcia, M.A. 1993: The role and enhancement of parasitic Hymenoptera: biodiversity in agroecosystems. In: LaSalle, J.; Gauld, I.D. ed. Intraspecific biodiversity in Hymmenoptera: implications for conservation and biological control. CAB International, Wallingford, England. Pp. 257-275.

Andow, D.A. 1991: Vegetational diversity and arthropod population response. Ann. Rev. Entomol. 36: 561-586.

Baggen, L.R.; Gurr G.M. 1998: The influence of food on Copidosoma koehleri (Hymenoptera: Encyrtidae), and the use of flowering plants as a habitat management tool to enhance biological control of potato moth, Phthorimaea operculella (Lepidoptera: Gelechiidae). Biol. Control 11: 9-17.

Berndt, L.A.; Wratten, S.D.; Hassan, P.G. 2002: Effects of buckwheat on leafroller (Lepidoptera: Tortricidae) parasitoids in a New Zealand vineyard. Agr. Forest Entomol. 4: 39-45.

Colley, M.R.; Luna, J.M. 2000: Relative attractiveness of potential beneficial insectary plants to aphidophagous hoverflies (Diptera: Syrphidae). Environ. Entomol. 29(5): 1054-1059.

Farber, S.C.; Constanza, R.; Wilson, M.A. 2002: Economic and ecological concepts for valuating ecosystems services. Ecol. Econ. 41(3): 375-392.

Ehler, L.E. 1998: Conservation biological control: past, present and future. In: Barbosa, P. ed. Conservation Biological Control. Academic Press, California, USA. Pp. 1-8.

Gurr, G. M.; Wratten, S.D. ed. 2000: Biological Control: Measures of Success. Kluwer Academic Publishers, The Netherlands. 429 p.

Gurr, G.M.; Wratten, S.D.; Barbosa, P. 2000a: Success in Conservation Biological Control of Arthropods. In: Gurr, G.M.; Wratten, S.D. ed. Biological Control: Measures of Success. Kluwer Academic Publishers, The Netherlands. Pp. 105-132.

Gurr, G.M.; Barlow, N.D.; Memmott, J.; Wratten, S.D.; Greathead, D.J. 2000b: A History of Methodological, Theoretical and Empirical Approaches to Biological Control. In: Gurr, G.M.; Wratten, S.D. ed. Biological Control: Measures of Success. Kluwer Academic Publishers, The Netherlands. Pp. 3-37.

Hawkins, B.A.; Mills, N.J.; Jervis, M.A.; Price, P.W. 1999: Is biological control of insects a natural phenomenon? Oikos. 86: 493-506.

Hickman, J.M.; Wratten, S.D. 1996: Use of Phacelia tanacetifolia flower strips to enhance biological control of aphids by hoverfly larvae in cereal fields. J. Econ. Entomol. 89: 832-840.

Hodgson, D.J.; Potter, M.A. 1993: The effect of water, glucose and pollen as dietary components on the longevity of adult Microctonus hyperodae (Hymenoptera: Braconidae, Euphorinae), a parasitoid of Listronotus bonariensis (Coleoptera: Curculionidae). Proc. 6th Australasian Conf. Grassl. Invert. Ecol.: 384-390.

Jervis, M.A.; Kidd, N.A. 1999: Parasitoid adult nutrition ecology: implications for biological control. In: Hawkins, B.A.; Cornell, H.V. ed. Theoretical Approaches to Biological Control. Cambridge University Press, UK. Pp. 131-147.

Kevan, P.G.; Baker, H. G. 1984: Insects on flowers. In: Huffaker, C.B.; Rabb, R.L. ed. Ecological Entomology. John Wiley \& Sons, New York, USA. Pp. 607-631.

Landis, D.A.; Wratten, S.D.; Gurr, G.M. 2000: Habitat management to conserve natural enemies of arthropod pests in agriculture. Ann. Rev. Entomol. 45: 175-201.

Lavandero, B.I.; Wratten, S.D.; Hagler, J.R. In press: Marking and tracking techniques for predators and parasitoids. Int. J. Pest Mgt Special Issue.

Poehling, H.M. 1989: Selective application strategies for insecticides in agricultural crops. In: Jepson, P.C. ed. Pesticides and Non-target Invertebrates. Intercept, Wimborne, Dorset, UK. Pp. 151-175.

Root, R.B. 1973: Organization of a plant-arthropod association in simple and diverse habitats: the fauna of collards (Brassica oleracea). Ecol. Monogr. 43: 95-124. 
Siekmann, G.; Tenhumberg, B.; Keller, M.A. 2001: Feeding and survival in parasitic wasps: sugar concentration and timing matter. Oikos 95(3): 425-430.

Solomon, M.E. 1969. Population Dynamics. Edward Arnold, London.

Speight, M.R. 1983: The potential of ecosystem management for pest control. Agric. Ecosys. Environ. 10: 183-199.

Thomas, M.B.; Wratten, S.D.; Sotherton, N. W. 1992: Creation of "island" habitats in farmland to manipulate populations of beneficial arthropods: predator densities and species composition. J. Appl. Ecol. 29: 524-531.

Waage, J.K. 1990: Ecological theory and the selection of biological control agents. In: Mackauer, M.; Ehler, L.E. Roland, J. ed. Critical issues in biological control. Intercept. Andover, UK. Pp. 135-158.

White, A.J.; Wratten, S.D.; Berry, N.A.; Weigmann, U. 1995: Habitat manipulation to enhance biological control of brassica pests by hover flies (Diptera: Syrphidae). $J$. Econ. Entomol. 88(5): 1171-1176.

Wratten, S.D.; Gurr, G.M. ed. 2000: Synthesis: The future success of biological control. In: Gurr, G.M., Wratten, S.D. ed. Biological Control: Measures of Success. Kluwer Academic Publishers, The Netherlands. Pp. 405-416.

Wratten, S.D.; Bowie, M. H.; Hickman, J.M.; Evans, A.M.; Sedcole, J.R; Tylianakis, J.M. 2003: Field boundaries as barriers to movement of hover flies (Diptera: Syrphidae) in cultivated land. Oecologia 134: 605-611. 